\title{
Etude sur la pathogénie et l'épidémiologie de la paralysie contagieuse des porcs à Madagascar
}

\author{
par H. SERRES
}

Bien que l'étude de la paralysie contagieuse du porc à Madagascar ait fait l'objet d'un nombre déjà important d'expériences, les modalités du mécanisme de la contagion naturelle ef le cheminement de l'ultra-virus jusqu'aux centres nerveux demeurent assez mal connus.

Les expériences qui vont être décrites ci-après ont été réalisées pour tenter de préciser ces points restés un peu dans l'ombre.

\section{LA PÉNÉTRATION DE L'ULTRA-VIRUS DANS L'ORGANISME}

Expérimentalement, la maladie peut être facilement reproduite par inoculation intracérébrale de substance nerveuse virulente, et, avec un succès moins régulier, par écouvillonnage des fosses nasales à l'aide d'un écouvillon infecté. Ces faits ont été observés par tous les chercheurs qui ont expérimenté avec le virus de Teschen.

Mais ces artifices ne sont pas comparables aux modes de pénétration naturels, au cours des épizooties.

Inutile, évidemment, d'envisager la voie intracérébrale ; mais même l'écouvillonnage nasal, qui entraîne des lésions de la muqueuse, avec hémorragies, ne se présente pas comme un procédé naturel.

La voie digestive a été maintes fois rendue responsable de l'infection des animaux. MARK (1) pense beaucoup aux aliments et boissons contaminés, opinion également exprimée par SÜSS (2) et RUMPL (3) en 1939. Des transmissions expérimentales ont été rapportées enfin par MAYR et WITTMANN (4) qui réussissent

Reçu pour publication : septembre 1960.

Rev. Elev. Méd. vét. Pays trop., 1960, 13, no 4.
7 fois sur 26 à l'aide de fortes doses de virus. A plusieurs reprises, nous avions fait absorber du virus par la bouche, aux animaux, soit pour tenter une immunisation per os, soit pour des raisons diverses.

Jamais nous n'avions eu de paralysie consécutive aux ingestions.

Tout dernièrement, nous avons repris ce problème avec un peu plus de précision. Une suspension de cerveau de porcelet à $10^{-1}$, et qui titre $10^{5} \mathrm{DL} 50$ (intracérébrale) par $\mathrm{ml}$, a été administrée d̀ raison de $5 \mathrm{ml}$ par voie buccale à cinq jeunes animaux de deux mois (soit $5 \times 10^{5}$ DL 50 par porc).

Aucun des animaux n'a présenté de trouble dans le mois suivant, et nous n'avons pas décelé l'apparition d'anticorps dans le sérum.

Nous ne doutons pas qu'on peut, comme l'ont fait Mayr et Wittmann, avec de très fortes doses, parvenir à contaminer des animaux; néanmoins, il ne paraît pas possible de penser, dans ces conditions, que la voie digestive puisse jover un rôle important dans la transmission naturelle à Madagascar.

Nous avons reporté notre attention sur la voie respiratoire, qui déjà paraissait fondamentale à MUSSEMEIER (5), puis DOBBERSTEIN (6) et FORTNER (7). Par des méthodes plus ou moins brutales, la transmission avait été réussie.

Nous avons choisi, afin de nous rapprocher de la nature, d'utiliser l'inhalation d'aérosols.

La première de nos expériences fut réalisée dans un local clos, dans lequel nous avions «brumisé » à l'aide d'un appareil Geosyl* une suspension de cerveau virulent à 10-2.

* Brumisateur L | Geosyl, Saint Denis. Seine. 
Nous disposions de dix porcelets d'une même portée ; six furent mis pendant une demi-heure dans le local, les quatre autres conservés comme témoins ont été mis en cohabitation avec leurs frères.

Les résultats furent les suivants:

- Parmi les six infectés:

Quatre meurent avec symptômes et lésions histologiques classiques, dans un délai de 12 à 14 jours.

Un est paralysé le douzième jour mais il guérira lentement.

Un est résistant.

- Parmi les 4 témoins :

Trois résisteront.

Un fera une paralysie tardive le 20 e jour, dont il mourra par la suite.

Le pouvoir infectant de l'aérosol nous parut dès lors important. Nous pensons que la maladie tardive de l'un des témoins peut s'expliquer par la contagion.

Nous avons alors entrepris l'étude de la sensibilité de la voie nasale, en nous efforçant d'être moins approximatif. Nous avons utilisé un appareil générateur d'aérosols pour thérapeutique humaine *, dont le masque de caoutchouc conique coiffe bien le groin des porcelets.

L'appareil diffuse, dans les conditions de l'expérience, $1,750 \mathrm{~g}$ en une demi-heure, soit très près de $1 \mathrm{mg}$ par seconde.

Si l'on utilise du cerveau virulent à $10^{-1}$, c'est $0,1 \mathrm{mg}$ de matière virulente qui est diffusé chaque seconde. Cette substance virulente a été par ailleurs titrée par intracérébrale sur des porcelets ; elle tue tous les animaux à la dilution $10^{-4}$ tandis que ceux inoculés à $10^{-5}$ et au delà demeurent tous indemnes.

A l'aide de l'aérosol, le temps minimum d'inhalation de cerveau à $10^{-1}$, qui provoque la maladie, est de 10 secondes.

On a donc d'une part, inoculé en intracérébrale $1 / 4$ de $\mathrm{ml}$ à $10^{-1}$ soit $2,5.10^{5} \mathrm{~g}$ de substance virulente, et d'autre part nébulisé $10^{-3} \mathrm{~g}$. Mais si dans l'intracérébrale tout l'ultra-virus pénètre dans l'organe sensible, il n'en est pas de même au cours de l'inhalation. Une faible

\footnotetext{
* Appareil « Alomisor ».
}

partie du virus nébulisé atteint ce lieu : tout d'abord l'expiration de l'animal est plus longue que l'inspiration, et pendant ce temps il n'y a pas de pénétration, mais rejet; ensuite, la majeure partie des fines particules inhalćes va s'adsorber dan's les poumons; or, les poumons ne constituent pas la porte d'entrée, puisqu'on peut $y$ introduire de fortes doses d'ultra-virus sans pour cela provoquer la maladie.

En admettant qu'au maximum 1/10 du virus nébulisé se fixe sur les muqueuses sensibles, on voit que le pouvoir infectant par aérosols est bien près d'égaler celui qu'on obtient par voie intracérébrale.

Tout cela nous conduit à penser que le virus malgache a certainement beaucoup de chances d'infecter les porcs en pénétrant par la voie respiratoire.

La commodité et l'efficacité de l'inoculation par aérosols, nous ont fait adopter la méthode pour de nombreuses expériences d'épreuve.

En faisant inhaler pendant 5 minutes une dilution à 10-1, le pourcentage de réussite de l'infection des porcelets neufs atteint 90 p. 100 , ce qui est pratiquement équivalent à ce que l'on obtient avec l'inoculation intracérébrale.

Nous avons pu observer que la période d'incubation a une durée plus constante que lorsque l'infection est faite directement dans le cerveau.

Les durées extrêmes sont de 6 jours et 30 jours par voie intracérébrale, de 10 jours et 20 jours par voie intranasale. D'autre part, entre le $10^{\mathrm{e}}$ et le $15^{\mathrm{e}}$ jour, 85 p. 100 des porcelets présentent les premières paralysies s'ils ont été infectés par aérosols, tandis que 50 p. 100 seulement développent leurs premiers symptômes au cours de ce délai, si l'inoculation a été faite dans le cerveau.

Quelles explications donner à ces observations?

On comprend que des incubations plus courtes soient obscrvées avec l'intracérébrale, le virus n'ayant pas à cheminer pour parvenir aux centres nerveux.

Mais pour expliquer la fréquence d'incubations plus longues, il faut peut-être considérer que toutes les zones du cerveau ne sont pas également sensibles; comme l'inoculation intracérébrale se fait de manière relativement aveugle, on pourrait pratiquer ou non l'injection en un point de sensibilité effective. 
Du point de vue clinique, il faut signaler la prédominance des symptômes encéphalitiques (mâchonnement, nystagmus, tremblements de la tête) au début de la maladie, après inhalation. Cela est beaucoup plus évident que lors de l'inoculation intracérébrale même, qui entraine assez souvent une paralysie primaire des postérieurs, avec la même souche.

Peut-être est-il utile de signaler ici que, dans la maladie spontanée, les formes d'emblée encéphalitiques s'observent, à l'heure actuelle, dans la plupart des cas.

\section{LE CHEMINEMENT DU VIRUS}

Ayant admis la possibilité de pénétration par voie respiratoire dans l'infection naturelle, il nous reste à déterminer le cheminement de l'ultra-virus, dans l'organisme du porcelet infecté.

Pour gagner les centres nerveux, plusieurs virus neurotropes empruntent la voie sanguine, ef l'on peut déceler une phase de virémie.

Nous avons recherché cette virémie tout au long de l'incubation et de la maladie clinique.

Deux porcelets furent infectés par aérosols et, deux fois par jour, ils furent l'objet de prises de sang (une le matin et une le soir). Chaque fois, $0,5 \mathrm{ml}$ de sang était inoculé en intracérébrale à un porcelet neuf.

Le premier des deux porcelets manifesta de la paralysie le $12^{\mathrm{e}}$ jour, et mourut le $13^{\mathrm{e}}$ jour. Il avait donné lieu à 26 inoculations. Le deuxième porcelet, paralysé le 14v jour, mourut le $15 \mathrm{e}$. Vingt-neuf porcelets neufs avaient reçu de son sang au cours de l'expérience.

Aucun des 55 animaux ainsi utilisés ne présenta le moindre trouble qu'on puisse rapporter à la paralysie contagieuse.

Notre recherche s'est avérée négative.

Il est bien évident que cela ne nous autorise pas à conclure à l'inexistence de la virémie : une phase très fugace aurait très bien pu nous échapper, malgré nos prélèvements toutes les 12 heures.

Nous avons d'autres raisons de ne pas craire au rôle de véhicule obligatoire du sang, au cours de la maladie.

Et tout d'abord, l'inoculation intraveineuse de doses massives d'ultra-virus, à des porcelets neufs, n'est pas suivie d'infection : A 10 animaux nous avons inoculé $5 \mathrm{ml}$ de suspension virulente titrant $10^{5} \mathrm{DL} 50$ par $\mathrm{ml}$, dans la jugulaire ; aucun des animaux n'a présenté le moindre trouble, au cours des six semaines suivantes.

Ensuite, il faut tenir compte de l'inactivité des anticorps sériques lorsqu'il s'agit d'enrayer la maladie, malgré leur pouvoir inhibiteur très important à l'extérieur de l'organisme.

Nous disposons de sérum hyperimmum, qui inhibe le pouvoir cytopathogène en culture de tissus, jusqu'à dilution de $1 / 4.000$. Si l'on inocule ce sérum à des porcelets de $10 \mathrm{~kg}$, on observe un pouvoir neutralisant du sérum des animaux dans les jours qui suivent, et qui se manifeste jusqu'aux dilutions:

1,8 si l'on a injecté $5 \mathrm{ml}$.

1,16 si l'on a injecté $15 \mathrm{ml}$.

1,32 ou 1/64 si l'on a injecté $50 \mathrm{ml}$.

L'infection par aérosols des porcelets le lendemain de l'administration du sérum, alors que les anticorps se sont répandus dans l'organisme, provoque la maladie comme sur les animaux neufs.

Il est à noter qu'au cours de l'incubation qui peut durer vingt jours, le taux d'anticorps circulants n'a pas tendance à varier beaucoup ; très certainement les anticorps provoqués par l'introduction de l'ultra-virus prennent le relais de ceux introduits par le sérum hyperimmum. Des prises de sang pour titrage faites tous les deux jours le montrent parfaitement.

Sur 25 porcelets ayant fait l'objet de l'expérience, deux seulement ont résisté à l'épreuve ; ce qui rejoint les résultats d'infection de porcelets neufs.

Les 23 animaux ayant succombé présentaient des anticorps circulants à des taux significatifs du moment de leur infection jusqu'à leur mort. On comprend mal comment le virus aurait pu emprunter la voie circulatoire pour gagner les centres nerveux dans ces conditions.

\section{L'EXCRÉTION DU VIRUS}

Toutes les recherches faites à ce jour ne nous ont pas permis de mettre en évidence l'ultravirus dans les selles des animaux, qu'ils soient malades ou en incubation.

Par contre, nous avons réussi la transmission avec l'écoulement nasal d'un malade, administré après filtration, par aérosol. 
II faut cependant signaler que deux autres assais se sont soldés par des échecs.

Cela porte à croire que l'élimination nasale du virus, si elle est possible, doit être irrégulière. Cette irrégularité pourrait être rapprochée des irrégularités que l'on voit dans la contagion naturelle; et c'est ici que nous rappellerons les remarques de notre confrère Lamberton* qui observait la recrudescence épizootique aux périodes de grand vent.

\section{CONCLUSIONS}

Les souches malgaches sont particulièrement neurotropes. La contagion paraît se faire par la voie aérienne, puisque les voies respiratoires nasales peuvent être soit porte d'entrée, soit voie d'élimination. Comme il ne semble pas qu'une phase de virémie intervienne, au cours de l'incubation, il est logique de penser que le virus prend le chemin le plus court, en se fixant d'abord sur les terminaisons nerveuses de la pituitaire, d'où il gagnerait les centres nerveux.

Les observations que nous avons pu faire ne concordent pas avec celles que viennent de publier en Allemagne Mayr et Hecke (8) qui font du virus de Teschen un entéro-neuro-virus, décelable dans de nombreux organes, susceptible d'engendrer un grand nombre d'infections inapparentes, se rapprochant ainsi de la poliomyélite humaine.

Bien que la parenté immunologique des virus malgaches et des virus européens ait été nettement mise en évidence par Lépine et Atanasiu (9)

\footnotetext{
* Communication personnelle.
}

dès 1950, il ne serait peut-être pas inutile de rechercher plus attentivement la personnalité de nos agents infectieux.

\section{RÉSUMÉ}

Les virus de la paralysie contagieuse à Madagascar paraissent plus exclusivement neurotropes que ceux étudiés actuellement en Europe, la contagion semblant se faire par la voie aérienne essentiellement.

Laboratoire central de l'élevage Tananarive.

\section{BIBLIOGRAPHIE}

1. MARK. - Berl. münch. tierärzl. Wochenschr. 1940, $56: 361$.

2. süss. - Wiener tierärzl. Wochenschr. 1939, $26: 641$.

3. RUMPL. - Wiener tierärzl. Monatschr. 1939, $26: 1$.

4. MAYR et WITTMANN. - Zschr. Immün. Forsch. 1959, $117: 45$.

5. MUSSEMEIER. - Berl. münch. tierärzl. Wochenschr. 1940, $48: 213$.

6. DOBBERSTEIN. - Zschr. Infekt. Haustiere, 1942, $59: 54$.

7. FORTNER. - Zschr. Infekt. Haustiere, 1942, $59: 91$.

8. MAYR et HECK.E. $-28^{\mathrm{a}}$ session Off. intern. Epiz. mai 1960, 54 : 438-44.

9. LÉPINE et ATANASIU. - Ann. Inst. Pasteur, 1950, $79: 113$.

\section{SUMMARY}

\section{Studies on the pathogenesis and epidemiology of Teschen Disease in Madagascar.}

The methods of natural infection in pigs in Madagascar have been studied as also the progression of the virus to the nerve centres and its excretion. The strains in Madagascar appear to be more exclusively neurotropic than those studied in Europe. Contagion is apparently air-borne, entering and being expelled via the nasal passages. Since there would appear to be no phase of viraemia during the incubation period, it is logical to assume, that virus takes the shortest routc, bccoming fixed firstly to the nerve endings of the pituitary and from thence reaches the nerve centres. 


\section{RESUMEN}

\section{Estudio sobre la patogenia y la epidemiología de la parálisis contagiosa del cerdo en Madagascar.}

El autor estudia las formas de contagio naturales de la parálisis contagiosa de los cerdos (enfermedadde Teschen) en Madagascar y el camino que el ultravirus sigue hasta alcanzar los centros nerviosos. Igualmente estudia las vias de eliminación.

Las cepas de Madagascar parecen más exclusivamente neurótropas que las estudiadas en Europa. El contagio parece realizarse por medio del aire, y las vias respiratorias nasales pueden ser, ya puerta de entrada, ya via de contaminación.

Como no se observa la presencia del virus en la sangre, el autor piensa lógicamente que sigue el camino más corto. Se fijaria en un principio sobre las terminaciones nerviosas de la pituitaria y seguiría la via nerviosa hasta los centros. 